\title{
Commentary 3 to the manifesto for the marine social sciences: unfolding Blue Growth
}

\author{
Maaike Knol-Kauffman ${ }^{1} \cdot$ Peter Arbo $^{1}$ \\ Published online: 3 July 2020 \\ (C) The Author(s) 2020
}

\section{A metaphor for transformation}

A marine social science manifesto is inherently an anticipatory exercise; it looks forward to the ocean and coastal challenges that societies are facing, with which marine social scientists are responsible to engage. The concept of Blue Growth that is mentioned in the manifesto (MMSS 1.1.3) and the related Blue Economy concept are also inherently anticipatory; they deal with a desired future for oceans and coasts, which are most explicitly inscribed in national and international ocean strategies (for example, European Commission 2017; FAO 2017). Generally, Blue Growth is a catchphrase that stands for the anticipated sustainable exploitation of ocean and coastal spaces and resources to support economic growth, thereby taking into account ecosystems, biodiversity, and social issues. Obviously, this is an idealized version of growth and sustainability.

What makes metaphors like Blue Growth so popular and useful is the fact that they are open and ambiguous. They allow for different interpretations. While some emphasize economic growth, driven by novel technologies, others see Blue Growth as a response to the global challenges of poverty, food security, pollution, and climate change. Therefore, "we must critically engage with the Blue Economy" (MMSS 1.1.3) and study how its developments materialize on the ground, and how these transform needs and societies at all scales. Due to decades of experience of engaging with, and intervening in, fisheries management, marine social sciences are equipped to deal with the challenges that the current and projected industrialization of the oceans bring along (Arbo et al. 2018; Bavinck et al. 2018; Bennett et al. 2017).

Maaike Knol-Kauffman

maaike.knol@uit.no

1 Norwegian College of Fishery Science, University of Troms $\varnothing$ - The Arctic University of Norway, Tromsø, Norway

\section{Expanding on a Blue Growth research agenda}

To engage with the Blue Economy in constructive ways, three important tasks for the marine social sciences are highlighted below.

\section{Practices of anticipation}

First, to understand how the Blue Economy unfolds, we need to better understand the processes around the construction, anticipation, and mobilization of ocean futures. The Blue Growth visions and strategies demonstrate the key role of scenarios, foresights, and other future studies. Such studies are now undertaken in a large variety of networked settings at different scales and with different scopes, ranging from general studies focusing on entire ocean economies to strategic, sectorspecific studies. The work is typically led by scientists and experts in close collaboration with policy makers, and other stakeholders are involved to varying degrees. These practices of anticipation constitute important sites of governance and politics, which set the premises and open some opportunities while closing others. As people act on the basis of their expectations, future images and narratives have a performative effect and can become self-fulfilling prophesies (Beckert 2016). Hence, it is vital to understand how such practices might prioritize certain interests and concerns over others, and how these prioritizations become real in their consequences.

\section{Dynamics of industrial development}

Second, the marine social sciences must enhance understanding of the dynamics of industrial development in ocean and coastal spaces, including their governance contexts. We need to better understand how new marine sectors expand, and what the drivers are for growth. This implies that we need to focus on the central actors 
in these sectors in terms of those who exploit, manage, and regulate developments. A better understanding is needed of the resources and infrastructures that are mobilized: the finances, capital, knowledge, legislation, materials, and personnel that make an industry work. Insight into the working of socio-technical systems and dynamics of technological innovation are crucial to be able to grasp the depths of Blue Growth.

\section{Integrated and ecosystem-based planning and management}

Third, there should be increased focus on the practices of integrated management, ecosystem-based management (EBM), and marine spatial planning (MSP) in order to understand the interactions between sectors and the socio-economic and ecological environments in which they operate (MMSS 1.2.4). EBM and MSP are implemented at regional, national, and sub-national levels, with the objective to take into account the interactions within an ecosystem as well as the cumulative human impacts on marine environments. There is an urgent need for comparative and critical research to understand how EBM and MSP are implemented in the context of new sectoral developments, such as seabed mining, renewable energy production, or the expansion of marine tourism into vulnerable areas like the Arctic. How are these frameworks designed, and to what extent do they enable or constrain the development of new activities? The design and implementation of monitoring and surveillance systems that follow status, trends, and impacts are pertinent objects for social science scrutiny.

\section{Toward desirable futures}

To conclude, while concepts like the Blue Economy and Blue Growth are abstract slogans, they are metaphors for ongoing and projected transformations of our oceans and societies that can and should be studied in detail, to learn and provide important lessons for sustainable governance. It is our task to study how Blue Growth unfolds on the ground, and our responsibility to engage with, and where possible intervene in these transformations, to help shaping desirable outcomes.

Funding Information Open Access funding provided by UiT The Arctic University of Norway.

Open Access This article is licensed under a Creative Commons Attribution 4.0 International License, which permits use, sharing, adaptation, distribution and reproduction in any medium or format, as long as you give appropriate credit to the original author(s) and the source, provide a link to the Creative Commons licence, and indicate if changes were made. The images or other third party material in this article are included in the article's Creative Commons licence, unless indicated otherwise in a credit line to the material. If material is not included in the article's Creative Commons licence and your intended use is not permitted by statutory regulation or exceeds the permitted use, you will need to obtain permission directly from the copyright holder. To view a copy of this licence, visit http://creativecommons.org/licenses/by/4.0/.

\section{References}

Arbo, P., M. Knol, S. Linke, and K.S. Martin. 2018. The transformation of the oceans and the future of marine social science. Maritime Studies 17 (3): 295-304.

Bavinck, M., S. Jentoft, and J. Scholtens. 2018. Fisheries as social struggle: a reinvigorated social science research agenda. Marine Policy 94: 46-52.

Beckert, J. 2016. Imagined futures: fictional expectations and and capitalist dynamics. Cambridge: Harvard University Press.

Bennett, N.J., R. Roth, S.C. Klain, K. Chan, P. Christie, D.A. Clark, G. Cullman, D. Curran, T.J. Durbin, G. Epstein, A. Greenberg, M.P. Nelson, J. Sandlos, R. Stedman, T.L. Teel, R. Thomas, D. Veríssimo, and C. Wyborn. 2017. Conservation social science: understanding and integrating human dimensions to improve conservation. Biological Conservation 205: 93-108.

European Commission. 2017. Report on the Blue Growth Strategy. Towards more sustainable growth and jobs in the blue economy, $\operatorname{SWD(2017)~} 128$ final.

FAO. 2017. Blue Growth Initiative: partnering with countries to achieve the Sustainable Development Goals. Retrieved from Rome

Publisher's note Springer Nature remains neutral with regard to jurisdictional claims in published maps and institutional affiliations. 